\title{
Analysis of the Social Experience of Children with Psychomotor Developmental Delay Followed at the Adjamé Child Guidance Center (Southern Côte d'Ivoire)
}

\author{
Adou Serge Judicaël Anoua ${ }^{1^{*}} \quad$ Issa Coulibaly $^{2}$ \\ 1.Department of Anthropology \& Sociology, Alassane Ouattara University, PO box V18, Bouaké, Côte d'Ivoire \\ 2.School Medical Service, General Direction of Budget and Finance, PO box V57, Abidjan, Côte d'Ivoire
}

\begin{abstract}
The research analyzed the social experience of children followed at the Adjamé child guidance center in Côte d'Ivoire for psychomotor developmental delays. This is a major concern given the difficulties in acquiring motor, cognitive, affective, sensory and social skills. Using a deterministic approach, 25 mothers with children with psychomotor developmental disorders were surveyed using a questionnaire on the socio-demographic characteristics of the children and their mothers, the clinical history of the children and the degree of their disorders, their social experience with parents and staff, and the mothers' suggestions. Parents live together and have income-generating activities. In many cases, apart from their parents, the children are in contact with people in the household. They are neither autonomous nor rejected by their peers in social relationships. Instead, they feel rejected by adults who attribute to them a negative social image as snake children, witch children. This plunges the parents into despair and desolation. This is why they suggest raising awareness in order to make the causes of this state of delayed psychomotor development of the child known and to bring about change. In this context, a holistic approach at several levels of intervention: individual, institutional, community and social, is necessary to deal with this discriminating and stigmatizing pathology. It is more than likely that this would contribute to solving the shortage of psychomotricians by increasing the number of these specialists in public facilities in order to optimize the care of children with developmental problems.
\end{abstract}

Keywords: Delayed psychomotor development, social experience, social integration, child morbidity

DOI: $10.7176 /$ RHSS/11-20-04

Publication date:October $31^{\text {st }} 2021$

\section{Introduction}

The psychomotor development disorder in children is a major concern in view of the difficulties in acquiring motor, cognitive, affective, sensory and social skills. In doing so, the child finds himself in a situation of polyhandicaps. This condition deprives them of all autonomy and makes them unable to acquire skills in accordance with their age.

On the subject, the literature gives us some explanatory logic. In this sense, Lamy, Laqueille, \& Thibaut (2015) found that children exposed to tobacco, cannabis, or cocaine during pregnancy would present more cognitive disorders such as attention, memory, and executive function disorders, behavioral disorders such as impulsivity, attention deficit hyperactivity, growth retardation, and psychiatric symptoms such as anxiety, depressive symptoms. For their part, Taiaa et al. (2017) observed that untreated Apert syndrome in a child explained his psychomotor developmental delay by the visual and neurological functional danger as well as the aesthetic damage following an unattended pregnancy. As for Bensaadi et al. (2016), consanguinity is a factor favoring Joubert syndrome, seen as a rare hereditary brain malformation, also characterized by delayed motor development. Besides these risky procreative behaviors, Alaoui et al. (2015) noted that atypical idiopathic hidradenitis occurring in children had an impact on their motor development such as delayed walking. Similarly, Benhammadi (2016) showed that immaturity of neural networks in children causes epilepsy that can interact with later brain development. This problem of anomalies in the child's developmental disorder was recognized by Souhila (2020) from speech therapy by the observation of disorders of perceptual functions penalizing the child on the level of exchanges and communication, then later on the school level. Furthermore, Asse et al. (2015) found that late systematic screening is one of the most common causes of psychomotor regression detrimental to the child in hypothyroidism. This same finding was observed by Niang et al. (2016) about late diagnosis and insufficient early management of children that were the cause of their more severe growth retardation and mental debility. All in all, it is undeniable that biological but especially human factors influence the disorder of psychomotor development in children. This situation justifies the current magnitude of this problem.

Indeed, Cecilia Baxter (2019) reminds us, according to the Global Disease Control Priorities Project, that 10 to $20 \%$ of the world's population would have developmental disorders. In the United States, this rate concerns $9 \%$ of children under 36 months of age. According to the same source, the lack of access to quality care during pregnancy or delivery and shortly after birth can contribute significantly to developmental disorders. In France, psychomotor developmental delay affects over $2 \%$ of children born (Lauriane, 2020). In countries with limited 
resources, there is a high risk of developmental delay in the four domains of motor, cognitive, sensory and language disorders (Masaya et al., 2020). In Côte d'Ivoire, the child guidance center in Abidjan recorded 1232 cases of psychomotor disorders, motor developmental delay, global developmental delay, hemiplegia, and cerebral palsy in 2014. In 2017, the Sainte Magdeleine psychomotor rehabilitation center recorded 56 cases of children with difficulties related to psychomotor development in children (Aguie, 2015).

It is true that this group of children is difficult to integrate into society. But it is possible to re-educate them in order to allow them to develop their intrinsic and extrinsic capacities required for social insertion, which depends on the child's autonomy. This possibility exists with the wide multidimensional and multidisciplinary range. Families and social groups should be aware of it and adhere to it. The management of the child with psychomotor disorders must be done promptly and especially early. To do this, physical exercises as a means of remediation of hypotonia in children with psychomotor delay would contribute to the improvement of the tonicity of this hypotonic child. In addition, in an institution, it is possible to follow the evolution of the condition of these children. At the same time, it is important to find out how they evolve in the family and community setting. Such a combination would help to broaden the view on psychomotor problems that threaten the harmonious development of children in order to accompany them effectively. Consequently, questions arise. Is the family and community environment of children followed for psychomotor developmental disorders stimulating? Is it rich in social interactions? In other words, is their immediate environment favourable to motor, cognitive, affective and sensory skills? How are these children with special needs perceived in their living environments? Faced with these questions, we propose the hypothesis that the image of children with psychomotor developmental delays hinders their social experience in the community. The quest for a quality of social life for these children requires the adoption of behaviors that promote their well-being. This article analyzes the social experience of children who are followed at the Adjamé child guidance center for psychomotor retardation.

To do this, the comparative approach helped to determine the socio-demographic characteristics of the children followed for psychomotor developmental delay as well as those of their parents, the clinical history of the children and the degrees of their disorders, the social experience of the children with their parents, and the parents' suggestions for improving the social experience of their children. The conduct of the research was based on a methodological procedure.

\section{Methodology}

\subsection{Research frame}

The research area was located in the commune of Adjamé in the autonomous district of Abidjan in southern Côte d'Ivoire. Within this geographical area, the child guidance center was the selected survey site. This child and family psychopathology referral service was created in April 1974. To date, the team of caregivers includes 1 child psychiatrist, 5 senior special education inspectors, 3 special educators, 2 special education teachers, 2 midwives specializing in psychiatry, 1 social worker, and 1 educational counselor. However, the center does not have a speech therapist, psychomotor therapist or occupational therapist. While its missions are to improve the health of the mother and child, to take care of children with psychopathological disorders, to participate in awareness, training and research activities, and to improve the socio-health and psycho-affective situation of children. To achieve these objectives, several activities are carried out. These activities include listening and interviewing, investigation or exploration and evaluation for diagnostic and etiological purposes, psychiatric, psychotherapeutic and socio-educational follow-up, speech therapy, psychomotor and psychoeducational rehabilitation, communication for behavioral change, parental guidance and theoretical and practical training in infant and juvenile psychopathology. In addition to these activities, the child guidance center plans to develop reeducational activities alongside the clinic, liaison psychiatry, taking into account perinatal psychopathology, setting up a day hospital and ensuring a role of facilitator, trainer and coordinator in the maternal and child protection services, school and pre-school structures, associations and youth clubs Following the presentation of the survey area, it is necessary to specify the nature of the research.

\subsection{Type of research and target population}

This research was of a descriptive-analytical type. It was based on a deterministic approach, according to which each effect of reality is produced by a cause that can be identified.

Mothers of children with psychomotor developmental disorders were surveyed in September 2020. This is due to the fact that most of the time, they are the ones who accompany these children. In this population, mothers who were seen at the center at the time of the survey and who had given their free and informed consent and whose children had a psychomotor developmental disorder of at least 6 months, and mothers of children who had been followed at the child guidance center for less than a year were included in the research. However, children under the care of guardians were excluded from the survey. This criterion made it possible to systematically select the respondents from an elementary survey based on an exhaustive list of the names of the 
mothers seen at the child guidance center at the time of the survey. However, a total of 25 mothers were interviewed. The survey was quantitative in nature. The objective was to obtain information on the social experience of children followed at the Adjamé child guidance center for delayed psychomotor development, according to the respondents.

\subsection{Ethics approval and data collection}

Prior to data collection, the ethical dimension was taken into account. Participants were informed about the research topic, its objectives and the range of survey activities. They were also informed about their role. To this end, their participation in this research was done on the basis of consent. To the point that, the ethical principles of anonymity, confidentiality and withdrawal rights were guaranteed for all participants. In the survey operation, the questionnaire was a data collection tool. In the field, the themes addressed through the individual interview were essentially the socio-demographic characteristics of the children followed for psychomotor developmental delay and those of their mothers, the clinical history of the children and the degrees of their disorders, the social experience of the children with the parents and the staff, and finally the suggestions of the mothers to improve the social experience of their children. The data were collected during 2 weeks from September 5 to 20, 2020, from 8:00 am to noon on working days, based on an individual and directed interview on the basis of the questionnaire.

\subsection{Data management and analysis}

The data collected in paper format during the interviews were recorded in the Epi Info software version 5.3 by entering the information. This computer processing was facilitated by the validation of the survey forms, the coding of the variables age, sex, place of residence, child custody, parents' occupation, marital status, siblings, family member, accompaniment of the child within the family, children's autonomy, children's language, interaction within the family, distance from the spouse, social image of the child, social interaction of the child, mothers' feelings, mothers' suggestion. From this treatment, the statistical description, the graphic presentation and the comparative method were used as a framework for analysis to establish rankings and proportions. This led to a better visibility of the facts concerning the socio-demographic characteristics of the children followed for psychomotor developmental delay as well as those of their mothers, the social experience of the children with the parents and the staff, and finally the suggestions of the mothers to improve the social experience of their children. From the information gathered, important ideas and trends contributed to the establishment of recommendations and advocacy for the creation of a school of psychomotricians in Côte d'Ivoire dedicated to the fight against psychomotor developmental delay in children.

\section{Results}

3.1. Socio-demographic characteristics

3.1.1. Socio-demographic profile of children with psychomotor developmental delay

Table1. Socio-demographic profile of children with psychomotor developmental delay

\begin{tabular}{|c|c|}
\hline \multicolumn{2}{|c|}{ Age } \\
\hline Age range & Percentage \\
\hline [6-12[ & $15.38 \%$ \\
\hline [12-18[ & $23.10 \%$ \\
\hline [18-24[ & $26.92 \%$ \\
\hline [24-30[ & $23.08 \%$ \\
\hline$[30-36[$ & $3.84 \%$ \\
\hline$[36-42[$ & $3.84 \%$ \\
\hline [42-plus [ & $3.84 \%$ \\
\hline \multicolumn{2}{|c|}{ Gender } \\
\hline Gender & Percentage \\
\hline Woman & $53.85 \%$ \\
\hline Man & $46.15 \%$ \\
\hline \multicolumn{2}{|c|}{ Place of birth } \\
\hline Place & Percentage \\
\hline Abobo & $23.13 \%$ \\
\hline Adjamé & $26.90 \%$ \\
\hline Angré & $3.85 \%$ \\
\hline Attécoubé & $3.85 \%$ \\
\hline Dokui & $3.80 \%$ \\
\hline Koumassi & $3.85 \%$ \\
\hline
\end{tabular}




\begin{tabular}{|c|c|}
\hline Macory & $3.85 \%$ \\
\hline Port Bouet & $7.69 \%$ \\
\hline Treichville & $3.85 \%$ \\
\hline Yopougon & $19.23 \%$ \\
\hline Guardian & Percentage \\
\hline Mother & $26.92 \%$ \\
\hline Father & $3.85 \%$ \\
\hline Both & $69.23 \%$ \\
\hline \multicolumn{1}{|c|}{ Age des enfants au début de la prise en charge } \\
\hline Age range at start of care & Percentage \\
\hline$[\mathbf{6 - 1 0}[$ & $19.24 \%$ \\
\hline$[10-13[$ & $42.31 \%$ \\
\hline$[\mathbf{1 3 - 2 0}[$ & $15.38 \%$ \\
\hline
\end{tabular}

Source: Survey data in Adjamé, September, 2020

The mean age was 21.42 months with a standard deviation of 10.92 and extremes of 9 to 60 months. The age range of 12 to 30 months represented $73.08 \%$ of the total number of children. The children surveyed were male in $53.85 \%$ of cases, for a sex ratio of 1.16 . The children surveyed lived in Adjamé, Abobo and Yopougon in $26.90 \%, 23.13 \%$ and $19.23 \%$ of cases respectively. The children lived with both parents in $69.23 \%$ of cases. The average age of the children at the beginning of care was 13.73 with a standard deviation of 5.63 and the extreme ages were 6 and 25 months. The 10 to 13 month age group represented $42.31 \%$.

3.1.2. Socio-demographic profile of parents of children with psychomotor developmental delay

Table 2. Socio-demographic profile of parents of children with psychomotor developmental delay

\begin{tabular}{|c|c|}
\hline \multicolumn{2}{|c|}{ Father's occupation } \\
\hline Occupancy & Percentage \\
\hline Unemployment & $3.85 \%$ \\
\hline Students & $7.69 \%$ \\
\hline Liberal & $38.46 \%$ \\
\hline Employee & $46.15 \%$ \\
\hline Other (religious) & $3.85 \%$ \\
\hline \multicolumn{2}{|c|}{ Mother's occupation } \\
\hline Occupation & Percentage \\
\hline Housewives & $15.40 \%$ \\
\hline Students and pupils & $15.40 \%$ \\
\hline Liberal & $46.10 \%$ \\
\hline Employees & $23.10 \%$ \\
\hline \multicolumn{2}{|c|}{ Marital status of parents } \\
\hline Marital status of parents & Percentage \\
\hline $\begin{array}{l}\text { Concubinage } \\
\end{array}$ & $23.08 \%$ \\
\hline Married & $50.00 \%$ \\
\hline Separated & $26.92 \%$ \\
\hline \multicolumn{2}{|c|}{ Siblings } \\
\hline Rank in siblings & Percentage \\
\hline First & $50 \%$ \\
\hline Second & $19.23 \%$ \\
\hline Third & $11.54 \%$ \\
\hline Fourth & $7.69 \%$ \\
\hline Fifth & $11.54 \%$ \\
\hline \multicolumn{2}{|c|}{ Other family members } \\
\hline Members & Percentage \\
\hline No person & $34.62 \%$ \\
\hline Housekeeper & $23.08 \%$ \\
\hline Grandparents & $26.92 \%$ \\
\hline Uncles, aunts, cousins & $15.38 \%$ \\
\hline
\end{tabular}




\begin{tabular}{|c|c|}
\hline \multicolumn{2}{|c|}{ Person who brought the disability to the parents' attention } \\
\hline Person & Percentage \\
\hline Grandparents & $19.23 \%$ \\
\hline Nurse or midwife & $3.85 \%$ \\
\hline Doctor & $38.46 \%$ \\
\hline Mother & $26.92 \%$ \\
\hline Neighbors & $11.54 \%$ \\
\hline
\end{tabular}

Source: Survey data in Adjamé, September, 2020

The fathers of the children surveyed were employed or self-employed in $46.15 \%$ and $38.46 \%$ of cases, respectively. The mothers of the children surveyed were employed or self-employed in $46.10 \%$ and $23.10 \%$ of cases respectively. The parents of the children surveyed were married in 50\% of cases. The children surveyed were the first siblings in $50 \%$ of cases. In addition to the parents, the siblings of the surveyed children, grandparents, aunts, uncles and cousins lived with the family in $65.38 \%$ of the cases. The parents' attention to the child's disability was drawn by doctors, nurses, midwives $(57.23 \%$ of the cases), in $42.77 \%$ of the cases the attention was drawn by the children's entourage.

These are the socio-demographic markers that remain influential factors in the situation of children with psychomotor developmental delay followed at the Adjamé child guidance center in Côte d'Ivoire. Beyond this description, we can also observe aspects of the social experience of these children that have an impact on their health.

\subsection{Social experience of the child with psychomotor delay}

3.2.1. Accompanying the child within the family

Table 3. Resumption of specific activities to accompany children at home

\begin{tabular}{|c|c|}
\hline \multicolumn{2}{|c|}{ Specific activities to accompany children at home } \\
\hline Activity & Percentage \\
\hline Massages & $100 \%$ \\
\hline Stretching & $100 \%$ \\
\hline Flexion-extension & $100 \%$ \\
\hline Verticalization & $38.46 \%$ \\
\hline Sitting positions & $69.23 \%$ \\
\hline Travel & $23.07 \%$ \\
\hline Games & $100 \%$ \\
\hline
\end{tabular}

Source: Survey data in Adjamé, September, 2020

Within the families, all the parents, i.e. $100 \%$, continue to play at home; sitting in $69.23 \%$ of cases, standing up in $38.46 \%$ of cases and moving around in $23.07 \%$ of cases.

3.2.2. Child's autonomy

Table 4. Concept of sphincter control

\begin{tabular}{|c|c|}
\hline \multicolumn{2}{|c|}{ Concept of sphincter control } \\
\hline Notion & Percentage \\
\hline No & $96.15 \%$ \\
\hline Yes & $3.85 \%$ \\
\hline
\end{tabular}

Source: Survey data in Adjamé, September, 2020

The children did not yet have sphincter control in $96.15 \%$ of cases.

Table 5. Sphincter control by age

\begin{tabular}{|c|c|c|c|c|}
\hline & \multicolumn{2}{|c|}{ Sphincter control } & & \\
\hline Age groups (months) & No & Yes & Total & $\%$ \\
\hline$[0-12]$ & 5 & 0 & 5 & 20 \\
\hline$[13-36]$ & 19 & 0 & 19 & 76.00 \\
\hline$[37-$ plus] & 1 & 1 & 1 & 4.00 \\
\hline TOTAL & 25 & 1 & 25 & 100 \\
\hline
\end{tabular}

Source: Survey data in Adjamé, September, 2020

Sphincter control was acquired by only one child who was in the age range of over 37 months. 
3.2.3. Integration of the child with psychomotor delay into the community and society 3.2.3.1. Child's language

Table 6. Type of language by age

\begin{tabular}{|c|c|c|c|c|c|c|}
\hline & \multicolumn{4}{|c|}{ Type of language } & & \\
\hline Age range (months) & Babbling & Some Syllables & Joint disorders & Vocalise & Total & $\%$ \\
\hline$[0-12]$ & 0 & 0 & 0 & 0 & 0 & 0 \\
\hline$[13-36]$ & 13 & 1 & 0 & 1 & 15 & 92,86 \\
\hline [37-more] & 1 & 0 & 1 & 0 & 2 & 7,14 \\
\hline TOTAL & 14 & 1 & 1 & 1 & 17 & 100 \\
\hline
\end{tabular}

Source: Survey data in Adjamé, September, 2020

No child had acquired language between 0 and 12 months. Children aged 13 to 36 months who had babble and vocalize as language represented $92.86 \%$.

3.2.3.2. Schooling of the child

Table 7. Schooling of the child

\begin{tabular}{|c|c|}
\hline \multicolumn{2}{|c|}{ Schooling of the child } \\
\hline Schooling & Percentage \\
\hline No & $96.15 \%$ \\
\hline Yes Reason for not enrolling the child in school \\
\hline Reason & $3.85 \%$ \\
\hline Doubts related to disability & Percentage \\
\hline The child is not of school age & $20.00 \%$ \\
\hline Later & $68.00 \%$ \\
\hline
\end{tabular}

Source: Survey data in Adjamé, September, 2020

Children were not enrolled in school in $96.15 \%$ of cases. Parents linked the lack of schooling to the young age of the children in $60 \%$ of cases.

3.2.3.3. Child's interactions within and outside the family

Table 8. Child's interactions within and outside the family

\begin{tabular}{|c|c|}
\hline Contact & Percentage \\
\hline No & $16.00 \%$ \\
\hline Yes Contact with children in the neighborhood \\
\hline Contact & $84.00 \%$ \\
\hline No & Percentage \\
\hline Yes & $3.77 \%$ \\
\hline Reason Reason for the child's lack of contact \\
\hline No idea child and other family members \\
\hline It is best if the child is at home & Percentage \\
\hline The child is always at home & $60.00 \%$ \\
\hline
\end{tabular}

Source: Survey data in Adjamé, September, 2020

Children had contact with other children and other family members in $84 \%$ of cases. The children were able to have contact with other children in their neighborhoods in 96.23 cases. No reason was given for the child's lack of contact with their neighbors in $60 \%$ of cases. 


\subsubsection{Perceptions of the child with delayed psychomotor development}

Table 9. Perceptions of the child with psychomotor developmental delay

\begin{tabular}{|c|c|}
\hline \multicolumn{2}{|c|}{ Perceptions of close relatives } \\
\hline Perception & Percentage \\
\hline It is not a person & $25.00 \%$ \\
\hline Snake child & $50.00 \%$ \\
\hline Witch child & $12.50 \%$ \\
\hline The caretaker in the village & $6.25 \%$ \\
\hline Cesarean section for the next birth & $6.25 \%$ \\
\hline Perception & Percentage \\
\hline It's a snake & $30.00 \%$ \\
\hline No idea & $30.00 \%$ \\
\hline He's a wizard who came to pay off a loan & $10.00 \%$ \\
\hline It is not a person & $30.00 \%$ \\
\hline
\end{tabular}

Source: Survey data in Adjamé, September, 2020

Close relatives perceived children as "snake children", "witch children" or children who were "not people" in $50 \%, 12.25 \%$ and $25 \%$ of the mothers of children surveyed respectively. Neighbors perceived the children as "snakes" (30\% of cases), witches (30\% of cases), and not people (30\% of cases).

3.2.5. Attitudes towards the child with delayed psychomotor development

Table 10. Attitudes towards the child with psychomotor delay

\begin{tabular}{|c|c|}
\hline \multicolumn{2}{|c|}{ Removal of the spouse upon discovery of the child's disability } \\
\hline Removal of the spouse & Percentage \\
\hline No & $76.92 \%$ \\
\hline Yes & $23.08 \%$ \\
\hline \multicolumn{2}{|c|}{ Reason for separation from spouse } \\
\hline Reason & Percentage \\
\hline No idea & $50.00 \%$ \\
\hline The father gives no explanation & $33.30 \%$ \\
\hline Lives in Europe & $16.70 \%$ \\
\hline \multicolumn{2}{|c|}{ Children's attachment to a parent } \\
\hline Attachment & Percentage \\
\hline Mother & $23.08 \%$ \\
\hline Father & $3.84 \%$ \\
\hline Both & $73.08 \%$ \\
\hline \multicolumn{2}{|c|}{ Parents' rejection of children with disabilities } \\
\hline Sense of rejection & Percentage \\
\hline No & $38.46 \%$ \\
\hline Yes & $61.54 \%$ \\
\hline \multicolumn{2}{|c|}{ Disappointment, denial, compassion of the parents in front of the situation of handicap of the children } \\
\hline Parents'feelings & Percentage \\
\hline Disappointment & $57.69 \%$ \\
\hline Hope & $7.69 \%$ \\
\hline Denial & $19.23 \%$ \\
\hline Compassion for the child & $15.39 \%$ \\
\hline
\end{tabular}

Source: Survey data in Adjamé, September, 2020

The parents had not separated when the child's disability was discovered in $76.92 \%$ of cases. For parents who were separated, no reason was given in $50 \%$ of cases. The children were attached to both parents in $73.08 \%$ of cases. The feeling of rejection was felt by $61.54 \%$ of the parents. Parents were disappointed, denied the child or had compassion in $57.69 \%, 19.23 \%$ and $15.39 \%$ of cases respectively. 
3.2.6. Parents' suggestions for improving children's social experience Table 11. Parents' suggestions for improving children's social experiences

\begin{tabular}{|c|c|}
\hline \multicolumn{2}{|c|}{ Suggestions from parents } \\
\hline Suggestions from parents & Percentage \\
\hline Improving research & $3.85 \%$ \\
\hline Create specialized schools & $7.69 \%$ \\
\hline Raising awareness for change & $42.31 \%$ \\
\hline Raise awareness of the causes & $26.92 \%$ \\
\hline Create several care centers & $7.69 \%$ \\
\hline Caring for children with disabilities & $7.69 \%$ \\
\hline Normal support for parents & $3.85 \%$ \\
\hline
\end{tabular}

Source: Survey data in Adjamé, September, 2020

The parents made suggestions in the sense of sensitization in order to make the causes known and to bring about change in respectively $26.82 \%$ and $42.31 \%$ of the cases.

This socio-demographic characterization of the children with psychomotor developmental delay and their mothers as well as their social experience leads to the search for an explanation for this state of affairs.

\section{Discussion}

This descriptive-analytical research described the socio-demographic characteristics of children with psychomotor retardation as well as those of their parents in order to analyze the clinical history of these children and their social experience.

\subsection{Socio-demographic characteristics of children}

Of the socio-demographic characteristics of the children, it was noted that the majority, $73.08 \%$, were cared for between 12 and 30 months with a mean age of 21.42 months, i.e. less than 3 years. The children seen in this research were relatively younger than those in the study by Kchaou et al. (2019) with a mean age of 3.7 years. In the context of this research, more than half of the children surveyed, or $54 \%$ of the cases and a sex ratio of 1.16 were male. This is consistent with the study by Bissouma and Té Bonlé (2010) where 57.3\% were male and the sex ratio was 1.3. Male children were therefore the most affected by psychomotor developmental delay. The children came from all the communes of Abidjan. None of the children resided in the interior of the country, contrary to the study by Bissouma and Té Bonlé in 2010, where $90 \%$ of the patients resided in Abidjan compared to $9 \%$ from the interior and $1 \%$ from abroad.

Furthermore, the fact that patients live outside of Adjamé can be seen as proof of the scarcity of public facilities for the care of children suffering from psychomotor retardation and can also be presented as a source of difficulties for these children. The absence of state structures for the rehabilitation of children with psychomotor disabilities in all the communes may explain the late treatment because of the long distance to travel and the lack of knowledge of the center.

However, the majority of the children (69.23\%) lived with both parents. In this regard, Winnicott (2017) stressed that the child needs both parents to develop well. For him, the presence of both parents is an asset for the education of children. In accordance with his theory, the involvement of both parents promotes the triangular relationship between the child, mother, and father. In the case of special needs children, the presence of both parents with the psychomotor handicapped child can reduce the difficulties related to the care of the child in terms of financial burdens, travel for rehabilitation sessions, accompaniment of the child within the family unit and psycho-affective support between the parents.

However, the average age of the children at the beginning of the care was $13.73 \%$ in this research. It was observed that the children are followed up after the first year. This leads us to note that the care of children suffering from psychomotor developmental delay is late. In the same sense, Dosso (2016) emphasized the late care of these children in institutions. Among other reasons for the delay, the denial of the child's situation, the gaze of others and the therapeutic route. Late care is detrimental for children because in any pathological situation early care gives more possibilities for the best results.

\subsection{Socio-demographic characteristics of parents}

Regarding the socio-demographic characteristics of the parents, most of the fathers of the children surveyed had a job in $84.30 \%$ of cases and the mothers in $69.20 \%$ of cases. Half, or $50 \%$ of the children surveyed had married parents. However, Lavoie (2017) stated that sometimes disability weakens the couple's ties. There is then a contradiction between the data of this research and that of this author. Based on the present results, there is no doubt that children live in married families. The marital status of the parents could be in line with Winnicott's (2017) theory in establishing the triangular relationship between these children and their parents. For him, this is 
essential for the development of the child, even when the child is not in a situation of disability. In the specific case of this research, the marital life facilitates the accompaniment of the child at home.

In addition, half, or $50 \%$ of the children were the first sibling. This result is close to the $45.8 \%$ for the first rank of siblings obtained by Nguefack et al. (2020). These are children whose parents lacked experience with the realities of childbearing, such as the course of pregnancy, labor, and delivery.

Overall, $65.38 \%$ of the children lived in the household with their grandparents, aunts, uncles and cousins in addition to their parents and siblings. This is conducive to the socialization of the child through interrelational exchanges, imitation, language babbling and the de-dramatization of the disability. In this context, Le Boulvais (2018) had stated that the interaction-rich family-type environment stimulates the development of the child with disabilities.

\subsection{Clinical history of children}

The present research revealed that these were children born to primiparous mothers. Nguefack et al. (2020) indicated in their work that first-born children were more exposed to psychomotor retardation. This links the primiparity of the mothers and the handicap of the children, since most of the first children were concerned. This confirmed the lack of experience of the mothers. Consequently, the primiparity of mothers without experience in childbirth could be at the root of dystocia, which is a source of cerebral suffering in the newborns. While all the mothers interviewed had attended all the required prenatal consultations. The children's problems therefore occurred during labor. This finding is similar to that of Belanger \& Caron (2018). Indeed, they showed that in $55 \%$ of cases, the disability had perinatal causes such as asphyxia and prematurity.

In addition, the research also revealed that no children were born from inbreeding. This is contrary to the study made by Gauthier (1992) in which he indicated the responsibility of consanguinity in children's disabilities. In the context of the Adjamé child guidance center, the situation of the children could therefore be attributable to the primiparity of the mothers and its corollaries such as dystocia.

\subsection{Accompanying the child within the family}

The research revealed that all the activities carried out at the center were taken up by parents to accompany their children at home through sitting, standing and moving respectively $69.23 \%, 38.46 \%$ and $23.07 \%$. All these activities are part of the care of the children along with the medical component, specific educational activities and parental guidance. Deshaies \& Miron (2020), referring to the importance of accompanying the child within the family, emphasized that the repetition of activities by the parents within the family unit helps to de-dramatize the situation and gives the child more opportunity to acquire skills by facilitating interactional exchanges. These interpersonal exchanges contribute to the child's development and socialization. At the Adjamé child guidance center, the children's social experience did not suffer from any discomfort because they were accompanied by their families.

\subsection{Social interactions}

The research showed that $71.43 \%$ of the children surveyed had only babbling as their language. This means that these children have a language delay for their age. Delayed psychomotor development is generally associated with language delay. In these conditions, inter-human exchanges remain poor. In most cases, $77 \%$, the parents had not separated since the discovery of the child's disability. This confirms the marital status of the parents and the good understanding in these families. This is not the case everywhere, since the child's disability is often a source of family conflict, separation of the parents or estrangement of the spouse.

However, it was noted here that more than half of the children $(63 \%)$ had social interactions with other children in their neighborhood. Similarly, Point (2013) showed that children with autism spectrum disorders could engage in social interactions with their peers.

\subsection{Social image of children}

The research noted that children were perceived by their relatives as snakes, child witches, or children who were not human beings in $50 \%, 12.25 \%$, and $25 \%$ of the children surveyed respectively. In addition, the perceptions of relatives were negative as noted by Menick (2015). For him, in Africa, physical or mental disability is a major component of stigma and marginalization.

These images on the children could explain the delayed care as parents first present them to traditional practitioners in the hope of finding the definitive solution. This prolongs their therapeutic journey. However, the children's situations are only the neuro-muscular after-effects of difficult and long deliveries linked to last minute errors. They are situations that have been established following pregnancies that were generally well monitored and proceeded normally. However, due to inexperience or decision errors, such situations do occur. In the same research context, the neighbors perceived the children as snakes ( $30 \%$ of the cases), wizards ( $30 \%$ of the cases), without being people (30\% of the cases). The neighbors had the same conceptions as the people close 
to the children. In contrast, Fontaine-Benaoum, Gaudron \& Paul (2015) noted in their work that mothers were more concerned about the lack of support.

\subsection{Parents' feelings about disability}

The research indicated that parents felt differently about their children's situations. More than half, 57.69\% were disappointed in the situation, $19.23 \%$ denied the child, and $15.39 \%$ of parents felt compassion for their children instead. This feeling is similar to that presented by Fontaine-Benaoum, Gaudron \& Paul (2015). For them, mothers felt anxiety and fear. This negative feeling corroborates the parents' suffering.

These images confine children and especially their parents to stigma and discrimination. Such attitudes are distressing situations for the parents of children with disabilities. In fact, the experience of children with psychomotor difficulties is marked by their rejection. This leads parents to denial, compassion and disappointment. Discouragement and despair are intense and very painful for the parents at the beginning of the treatment at the center. Crying and crying from the heart are frequent at this time of the child's care.

From this analysis, the follow-up of the child is also a means of therapy for the parents of the children. Indeed, during the first interviews, almost all the parents burst into tears. This proves their suffering, especially moral suffering. However, the follow-up of the child gives hope. Thus, it happens that the parents benefit from re-education sessions with a parental guidance background in order to see hope reborn and the situation dedramatized. Some manage to support the parents at the beginning of the treatment. With this in mind, and wanting to confirm this opinion, a small group of three mothers was formed, including the mother of a child who had been followed for several months. The most senior mother played the role of support group facilitator. This exchange group helped to overcome the despair. As a result, one could be convinced that parents need support and to be informed about the possibilities of their children's progress. This is especially true since the population needs to be made aware of the causes of developmental delays in children and of the chances of their children's favorable evolution. Moreover, early treatment would offer more possibilities for a healthy life to the child with psychomotor developmental delay.

\section{Conclusion}

The research has made it possible to analyze the social experience of children followed at the Adjamé child guidance center for delayed psychomotor development. However, it has some limitations. Its cross-sectional nature does not allow for the search for cause and effect, and the generalization of results is not obvious because it was conducted in one survey site. However, the study revealed that children are taken into care with delay. Children from dystocic deliveries are at the top of the list of siblings. The parents live together and have incomegenerating activities. In many cases, apart from their parents, the children are in contact with other people in the household. They are not autonomous and in their social relationships, they are not rejected by their peers. On the other hand, they feel rejected by adults who attribute to them a negative social image such as snake children, witch children. These negative metaphors plunge the parents into despair and desolation. This implies that the children's social experience is marked by stigmatization. Therefore, parents suggest awareness raising in order to make known the causes of this state of delayed psychomotor development of the child and to bring about change. In this context, a holistic approach at several levels of intervention: individual, institutional, community and social, is necessary to deal with this discriminating and stigmatizing pathology. This includes avoiding consanguineous marriages, continuing educational activities for children within the family unit, regular prenatal consultations and emergency evacuation in case of prolonged labor in childbirth, awareness-raising in the communities by the Abidjan child guidance center in order to de-dramatize the situation of the children, the formation of psychological support groups by first contact parents to share experiences in the management of children, the training and provision of speech therapists and psychomotricians, and the construction of follow-up centers for children with developmental disorders. In addition, following the example of the existence of a school for speech therapists at the National Institute for the Training of Health Workers (INFAS) in Abidjan, the creation in the medium term of a school for the training of psychomotricians in this same institute is a guarantee of effectiveness. It is more than likely that this would contribute to solving the shortage of psychomotricians by increasing the number of these specialists in public facilities in order to optimize the care of children with developmental problems.

\section{References}

Aguie, M. L. B. (2015). Motor exercises, means of acquisition of sitting by the child with cerebral palsy. End of cycle thesis, Abidjan INFS, Schools of Specialized Educators.

Alaoui, I. H., Hocar, O., Akhdari, N., Amal, S., Hakkou, M., Hokoumi, G., Draiss, G., \& Bouskraoui, M. (2015). An unusual cause of delayed gait acquisition: idiopathic palmoplantar hidradenitis. Archives of Pediatrics, 22(3), 306-308. https://doi.org/10.1016/j.arcped.2014.12.010

Asse, K.V., Yenan, J.P., Plo, K.J., Yeboua , K.R., Aka, A., Yao, K.C. (2015). Psychomotor delay revealing 
congenital hypothyroidism in a 14-month-old infant in Bouaké, Côte d'Ivoire. Revue Internationale des Sciences Médicales d'Abidjan, 17, 1:16-20. https://doi.org/10.1016/j.arcped.2014.12.010

Bélanger, S. A., \& Caron, J. (2018). Assessing the child with global developmental delay or intellectual disability. Paediatrics \& Child Health, 23(6), 411-419. https://doi.org/10.1093/pch/pxy099

Benhammadi, I. (2016). The contribution of relational to psychomotor development in children with epilepsy. Journal of "TATWIR", 3(1), 226- 234.

Bensaadi, N., Iddir, S., Lounis, M., Benghadid, W., \& Chalah, S. A. (2016). Joubert syndrome: a genetic cause of recurrent infant apnea. Neurological Journal, 172, A57. https://doi.org/10.1016/j.neurol.2016.01.133

Bissouma, A-C., Té Bonlé, D. M. (2010). Les retards psychomoteurs au Centre de Guidance Infantile d'Abidjan (Côte d'Ivoire) Revue Internationale des Sciences Médicales, 12(2): 34-38.

Cecilia Baxter, MD. 2019. Prenatal risk factors for developmental delay in the newly arrived child in Canada. [Online] Available: https://www.enfantsneocanadiens.ca/mental-health/prenatal-risk (August , 2021)

Deshaies, I., \& Miron, J. M. (2020). Weavers of childhood: The development of the 4- and 5-year-old child. JFD Publishing.

Dosso, K. (2016). Manual activities as a means to improve fine motor skills in a child in a special institution. Dissertation of end of cycle INFS Abidjan, Schools of Specialized Education Masters.

Fontaine-Benaoum, É., Gaudron, C. Z., \& Paul, O. (2015). Parenthood in the face of a child's disability. Childhood, (3), 333-350. https://doi.org/10.4074/S0013754515003067

Gauthier, S. (1992). Autosomal recessive diseases in the Saguenay-Lac-St-Jean region: a study of consanguinity and kinship. Université Laval.

Kchaou, K., Kammoun, I., Rim, K., Masmoudi, D., Asma, H., Triki, L., \& Kaouther, M. (2019). Should we fear a febrile seizure in a child with psychomotor delay? Neurological Journal, 175, S52. https://doi.org/10.1016/j.neurol.2019.01.154

Lamy, S., Laqueille, X., \& Thibaut, F. (2015). Potential consequences of tobacco, cannabis and cocaine use by pregnant women on pregnancy, newborn and child: a review of the literature. The Brain, 41, S13-S20. https://doi.org/10.1016/j.encep.2014.08.012

Lauriane, G. (2020). Evaluation of psychomotor development in children under 3 years of age and difficulties encountered in general practice: a qualitative study of 14 doctors in Bearn. Thesis of General Medicine, University of Bordeaux. dumas-02866558e

Lavoie, A. (2017). The experience of parents with a child with a health or developmental problem. Portraits and trajectories, 20: 1-24.

Le Boulvais, S. (2018). It can all start with a simple look...: parental gaze at the heart of psychomotor solicitations: resources to support parenting in psychomotor development. Human medicine and pathology. dumas-02075886e

Masaya, A. M., De Cock, P., Natuhoyila, A. N., Ndosimao, C. N., \& Bempui, B. P. M. (2020). Assessment of psychomotor development of the Congolese child by the Bayley scale for child development second edition. Pan African Medical Journal-Clinical Medicine, 2(56): 1-13. doi: 10.11604/pamj-cm.2020.2.56.20980

Menick, D. M. (2015). Social and cultural representations of childhood disability in Black Africa. Psy Perspectives, 54(1), 30-43. https://doi.org/10.1051/ppsy/2015541030

Nguefack, S., Tetinou, F. D., Sitchepin, N. M., Agbor, M. A., Chiabi, A., Kago, D., \& Nguefack, F. D. (2020). Malnutrition in children with psychomotor retardation in Yaoundé-Cameroon: a case control study. [online] Avaiable https://www.researchgate.net/publication/341343178_Malnutrition_chez_les_enfant_avec_retard_de_devel oppement_psychomoteur (September, 2021)

Niang, B., Fall, A. L., Ba, I. D., Keita, Y., Ly, I. D., Ba, A., Thiongane, A., Ndongo, A. A., Boiro, D., Thiam, L., Ba, A., Houngbadji, M., Fattah, M., Djeng, Y. J., Cissé, D. F., Basse, I., Sylla, A., Faye, P. M., Diouf, S., Ndiaye, O., \& Sarr, M. (2016). Congenital hypothyroidism in Dakar: about 28 cases. The Pan African Medical Journal, 25.46: 1-6. doi: 10.11604/pamj.2016.25.46.10321

Point, M. (2013). Children with pervasive developmental disorder in inclusive childcare settings: the nature of social interactions during free play periods (Doctoral dissertation, Université du Québec à Trois-Rivières).

Souhila, B-Z. (2020). Neurovisual impairment and disturbances in oral language acquisition in cerebral palsy children: about a rehabilitated case. AL-LISĀNIYYĀT, 26 (2): 16-31.

Taiaa, O., Amasdlm, S., Fikri, M., Elkhamlichi, A., Sefiani, A., Elhassani, M. R., \& Jiddane, M. (2017). A rare cause of bilateral exophthalmos in children. Journal of Neuroradiology, 44(2), 105. https://doi.org/10.1016/j.neurad.2017.01.079

Winnicott, D., W. (2017). The child and his family. Payot: "Petite Bibliothèque Payot," 256 pp. 